\title{
Breve debate historiográfico sobre a evolução da filosofia da história: uma revisão de literatura
}

A História como área de conhecimento se tornou altamente científica em termos de pesquisa especializada, e são eficientes na resolução de problemas cognitivos, mas esses conhecimentos produzidos e analisados somente de forma técnica teriam algum impacto sobre a forma que o homem vê o mundo ou da melhoria de algum aspecto social ou cultural? Este trabalho tem como intuito realizar um breve estudo a respeito da conceitualização de Filosofia da História, dando enfoque no seu desenvolvimento ao longo do tempo, em que passou pelas vertentes dominantes em cada época como a teologia, o iluminismo e a firmação do caráter técnico-científico da história na modernidade. A presente pesquisa trata - se de uma revisão bibliográfica descritiva e exploratória, desenvolvida a partir de materiais publicados em livros e artigos, visando o aprofundamento do estudo em questão. Conclui-se com este trabalho que a Filosofia da História passou por diversas transformações durante sua história e agora está inclinada a trabalhar os aspectos da Teoria da História ou Epistemologia devido ao forte cunho científico da pesquisa acadêmica atual. Pode-se afirmar que a própria evolução da Filosofia da História é um termo de estudo histórico a qual é possível realizar análises dos trabalhos dos historiadores de cada período e sua relação com o contexto social, político e religioso.

Palavras-chave: História; Filosofia; Revisão.

\section{Brief historiographic debate on the evolution of historical philosophy: a literature review}

\begin{abstract}
History as a field of knowledge has become highly scientific in terms of specialized research, and are efficient in solving cognitive problems, but this knowledge produced and analyzed only in a technical way would have some impact on the way that man sees the world or improvement any social or cultural aspect? This work aims to carry out a brief study about the conceptualization of Philosophy of History, focusing on its development over time, in which it passed through the dominant strands in each era such as theology, enlightenment and the establishment of the technical- scientific framework of history in modern times. This research is a descriptive and exploratory bibliographic review, developed from materials published in books and articles, aiming to deepen the study in question. It is concluded with this work that the Philosophy of History has undergone several transformations during its history and is now inclined to work on aspects of Theory of History or Epistemology due to the strong scientific nature of current academic research. It can be said that the evolution of the Philosophy of History itself is a time of historical study which is possible to carry out analyzes of the works of the historians of each period and their relationship with the social, political and religious context.
\end{abstract}

Keywords: Story; Philosophy; Review.

Topic: História das Teologias e Religiões

Reviewed anonymously in the process of blind peer.
Received: $15 / 11 / 2020$

Approved: 21/03/2021
Greyg Lake Oliveira Costa

Universidade Federal do Tocantins, Brasil http://lattes.cnpq.br/2969706963152999 greyg08lake@gmail.com

Marcos Alexandre de Melo Santiago Arraes (iD)

Universidade Federal do Tocantins, Brasil

http://lattes.cnpq.br/6477645030306199

http://orcid.org/0000-0002-8893-6561

marcos.arraes@mail.uft.edu.br

Rita de Cassia Guimarães Melo (iD)

Universidade Federal do Tocantins, Brasil

http://lattes.cnpq.br/3717304992656417

http://orcid.org/0000-0002-7067-6079

ritaguimaraes@mail.uft.edu.br

d

DOI: 10.6008/CBPC2595-430X.2021.001.0002
Referencing this:

COSTA, G. L. O.; ARRAES, M. A. M. S.; MELO, R. C. G.. Breve debate historiográfico sobre a evolução da filosofia da história: uma revisão de literatura. Social Evolution, v.5, n.1, p.7-12, 2021. DOI: http://doi.org/10.6008/CBPC2595-430X.2021.001.0002 


\section{INTRODUÇÃO}

Nos setores da cultura atual do pensamento histórico existe a premissa que o conhecimento produzido no passado no âmbito da historiografia acadêmica é obsoleto, e não apresenta valor ideal no presente momento. A História como área de conhecimento se tornou altamente científica em termos de pesquisa especializada, e são eficientes na resolução de problemas cognitivos, mas esses conhecimentos produzidos e analisados somente de forma técnica teriam algum impacto sobre a forma que o homem vê o mundo ou da melhoria de algum aspecto social ou cultural?

Este é um questionamento que acompanha a evolução da História. Assim, a procura do sentido de o porquê estudar o passado, foi o grande norteador do que hoje é conhecida como a Filosofia da História, ou seja, os questionamentos a respeito do sentido dos acontecimentos históricos, e não apenas um simples levantamento de dados que apesar de reunir uma grande quantidade de informações históricas importantes que a séculos atrás seriam impossíveis serem levantados devidos às limitações tecnológicas da época, não expressam o contexto filosófico do período.

Portanto entende-se por Filosofia da História uma interpretação do processo histórico a partir de um fim previamente estabelecido, sem se prender a datas específicas, ou ainda, como esclarecimento de um sentido ou direção única e inflexível do trajeto da humanidade ao longo do tempo em direção a um resultado, seja ele de caráter religioso ou material, opera com a ideia de término do processo histórico em um ponto ideal de chegada para o ser humano (ROIZ, 2008).

Assim este trabalho tem como intuito realizar um breve estudo a respeito da conceitualização de Filosofia da História, dando enfoque no seu desenvolvimento ao longo do tempo, em que passou pelas vertentes dominantes em cada época, como a teologia, o iluminismo e a firmação do caráter técnicocientífico da história na modernidade.

\section{METODOLOGIA}

A presente pesquisa trata - se de uma revisão bibliográfica descritiva e exploratória, desenvolvida a partir de materiais publicados em livros e artigos, visando o aprofundamento do estudo em questão. Nesta revisão de literatura foram utilizados artigos das bases de dados Scielo, Google scholar, e Livros publicados. Para a pesquisa foram selecionados artigos no idioma, português, sem recorte temporal. Utilizou-se as palavras-chave: Filosofia, História, Teologia, Metafísica e História moderna. Os critérios de inclusão foram a leitura completa dos artigos e em seguida a inclusão dos trabalhos que estavam relacionados com o tema. Os critérios de exclusão de estudos foram os trabalhos que não apresentaram boa qualidade metodológica ou não abordaram diretamente o tema. Essa pesquisa foi coletada por um único pesquisador com a finalidade de descrever brevemente o processo de desenvolvimento da Filosofia da História.

\section{DISCUSSÃO TEÓRICA}

Introdução a filosofia da história 
A Filosofia da História pode ser definida como a busca humana pelo sentido da presença do ser humano no tempo. De maneira inevitável esta questão se defronta com os problemas referentes ao significado do já ocorrido na História do homem e ao mesmo tempo com as demandas sobre o que estas experiências agregam para o futuro da humanidade. Assim a busca deste pensamento crítico de forma reflexiva proporciona uma qualificação do caráter filosófico, o que permite a indagação do sentido do ser humano e sua autocompreensão a partir daquilo que já foi realizado no passado (BARROS, 2009).

Os estudos a respeito da história da humanidade é um ponto que historicamente despertou interesse de muitos filósofos. A história em si tem por finalidade evocar noções filosóficas e apresentar um significado de eventos históricos, se tornando assim uma ferramenta de reflexão das escolhas e circunstâncias que levaram a uma determinada situação. Essas reflexões filosóficas baseando-se na própria História e na natureza do conhecimento histórico pode ser agrupada em uma unidade conhecida como Filosofia da História (ITTLE, 2016).

Genericamente, a Filosofia da História é definida em razão de três grandes períodos da história do pensamento. Iniciando pela Filosofia da História Teológica, também conhecida como Filosofia da História Providencial, correspondendo principalmente à concepção cristã de tempo por Agostinho no início da idade média. A Filosofia da História Metafísica, também denominada de especulativa, que data desde as concepções de história da humanidade ou história filosófica, que ganhou muito destaque no século XVIII. E por fim, a Filosofia Crítica da História também definida como Epistemologia ou Teoria da História, que remota a introdução da análise de cunho científico nas análises históricas características do século XIX (JULIÃO, 2010).

Segundo Bourdé et al. (1983), a filosofia da história se solidificou no século XVIII, durante o iluminismo. Período em que surgem os primeiros conceitos de matéria, evolução das espécies e do progresso do ser humano. Os principais pensadores da época como Voltaire, Kant e Condorcet tinham como pressuposição a ascendência da humanidade em direção a um estado ideal. O grande florescimento da Filosofia da História surgiu durante a revolução francesa no século XIX, tendo premissas religiosas ou ateias que buscavam descobrir um sentido para história.

Já Pimenta (2014), propõe uma discussão mais aprofundada sobre a concepções de que a Filosofia da História teve sua origem no século XVIII, onde o autor cita trabalhos como o de Gibbon (1761, citado por PIMENTA, 2014) "Se nem todos os filósofos são historiadores, seria ao menos desejável que todos os historiadores fossem filósofos". Gibbon afirma ainda que apenas dois historiadores até então tinham o caráter filosófico, sendo eles, Tácito na antiguidade e Montesquieu na época moderna.

De acordo com Silva (2017), o termo filosofia da história foi realmente proposto por Voltaire, e seu objetivo era diferenciar a Filosofia da Teologia da História. Como consequência, alguns estudiosos afirmam que Agostinho desenvolveu uma Teologia da História e não uma Filosofia da História. Entretanto, ao se tomar a definição de Filosofia da história como a ideia de interpretação sistêmica, a obra De Civitate Dei de Agostinho se trata de uma Filosofia Histórica. Estando de acordo com as ideias de Löwith, que afirma que a filosofia da história está em total dependência da Teologia da História, principalmente no aspecto Teológico 
da História como uma história de realização e salvação.

Marx que foi um dos grandes opositores das ideias de Hegel, a qual buscava unificar a filosofia com o cristianismo, acabou criando sua própria história escatológica, a qual contava uma história de redenção e conquista do proletariado, sendo o povo escolhido, se caracterizando como materialismo histórico.

Segundo Löwith, o materialismo histórico e o cristianismo são intimamente ligados, não podendo ser considerado a existência do mesmo sem a influência cultural da tradição judaico-cristã sobre Marx. Por fim, o pensador acredita que a providência, apesar de ser de origem divina, também é fruto da razão, pois se trata de uma verdade que condiz com a própria afirmação que a razão governa o mundo, apenas não é totalmente compreendida pelo homem, exceto em casos isolados sobre condições específicas. Assim o plano de Deus pode ser apresentado ao homem e cabe ao mesmo usar seu intelecto para compreender através da razão as intenções divinas (NERI, 2019).

\section{Filosofia da história teológica}

A Filosofia da História Teológica pode ser caracterizada com os seguintes aspectos conceituais de acordo com Collingwood (1972), sendo elas universalidade, providência, apocalíptica e periodização.

Com relação ao aspecto universal, o autor acredita que a história cristã sofreu uma revolução Copérnica, por meio da qual foi destruída a própria ideia de centro de gravidade. Em contrapartida Clark (2013), discorda das afirmações de Collingwood (1972) onde a ideia de centro de gravidade não é destruída, mas sobre um processo de transformação de geograficamente localizado para o geograficamente disperso; e de espiritualmente diverso modificado para espiritualmente unificado e constante. $O$ centro de gravidade, segundo Agostinho, deixa de ser geográfico e passa a ser espiritual.

Sobre o aspecto da providência Agostinho afirma que os acontecimentos históricos não dependem do posicionamento dos astros e Collingwood (1972) adiciona a ideia de que a filosofia cristã da história atribui os acontecimentos da história a atuação da providência que pré-estabelece seu curso e não pela sabedoria do agente humano. Nesse aspecto a Filosofia da História Teológica pressupõe que a história não é resultado de ação humana, nem das forças sociológicas, ou do materialismo dialético, nem mesmo de quaisquer outras combinações, mas da Providência agindo através de causas secundárias ou poderes intermediários (SILVA, 2017).

O aspecto apocalíptico, faz da morte e ressurreição de Cristo eventos centrais da história, que segundo Silva (2017):

Ele parece restringir esses eventos, dando a eles uma conotação prospectiva e retrospectiva: "a primeira... consistindo numa preparação cega para um acontecimento ainda não revelado; a segunda... dependente do facto de a revelação se realizar agora". Mas Agostinho, quando comenta a invasão dos bárbaros, ressalta que apenas Jesus é quem protegeu as pessoas, sendo que os deuses dos romanos para nada serviram. Ou seja, os eventos apocalípticos da morte e ressurreição de Cristo têm detalhes futuros significativos que foram ignorados por Collingwood.

E por fim a periodização que nada mais é que a divisão cronológica utilizada na separação do tempo histórico da humanidade, não tendo nenhuma especificação relevante ao tema tratado neste capítulo. 


\section{A filosofia da história metafísica}

A filosofia da história metafísica teve origem no século XVIII, como já mencionado, e o grande marco foi a desvinculação da história da filosofia com as ideias teológicas, como Kant exprimiu a sua reflexão sobre a história, em que na sua hipótese afirma que no curso absurdo dos assuntos humanos e na acumulação dos fatos há história empírica, é possível vislumbrar um propósito, entretanto o mesmo não foi concebido segundo o pensador, por uma inteligência superior. E que a tendência de evolução do homem como ser não é atingir um estado perfeito da natureza, mas sim um estado perfeito de cultura (BOURDÉ et al., 1983).

Outro pensador de expressão, associado aos conhecimentos filosóficos da História Metafísica foi Hegel, que acreditava na força da razão. No qual incentivava seus alunos a terem confiança na ciência e fé na razão. Ainda assim, Hegel era ligado fortemente à religião e vê em sua filosofia um desenvolvimento de protestantismo, se propondo a elevar sua fé luterana do sentimento subjetivo à certeza racional. Em suas obras é possível distinguir três categorias intelectuais, a lógica trata da ideia abstrata, a filosofia da natureza que examina a difusão da ideia fora de si, no mundo natural e a filosofia do espírito, que se interessa pela tomada de consciência do espírito através da história universal.

Voltaire por sua vez, influenciado pela sua carreira como poeta é um filósofo historiador que tinha uma visão mais artística sobre os relatos históricos, no qual entendia que o historiador deveria focar em grandes heróis, sendo necessário ao historiador agradar com a sua escrita de forma breve sem poluir seu relato com detalhes irrelevantes, obviamente com informações sólidas, mas que seja expressada de forma filtrada pelo historiador (PECORARO, 2009).

Em síntese a Filosofia da História Metafísica, se trata de em uma reflexão prioritariamente filosófica, que apresenta como parâmetro da elucidação do motor da História, a vontade, a razão e a liberdade sendo categorizada em (transcendentalmente) constituintes ou (ontologicamente) determinantes do processo histórico.

\section{Filosofia crítica da história}

A Filosofia Crítica da História tem por objetivo realizar uma análise epistemológica a respeito das condições de um conhecimento científico da história, tendo por característica principal ser preponderantemente analítica, outro objetivo é amparar as concepções de acordo com o princípio básico do desenvolvimento histórico consistindo de certos fatores fundamentalmente materiais e antropológicos, como por exemplo: as analogias políticas, sociais e econômicas, os fatores geográficos, as raças e os aspectos psicológicos (JULIÃO, 2010).

Em determinadas áreas do conhecimento contemporâneo existe uma tendência em desvalorização de pensamentos históricos com sustentação na premissa que o conhecimento produzido no passado no âmbito da historiografia acadêmica não tem importância na vida atual. Essa avaliação assume que, com o avanço profissional de especialização sobre os conhecimentos históricos, ocasionou um distanciamento entre o conhecimento de aspectos do passado com as exigências por resolução de problemas atuais (ASSIS, 
2017).

Esse fenômeno ocorreu principalmente pela profunda renovação do campo científico, ocorrida nos últimos 40 anos. Uma das principais mudanças que pode ser observada na atualidade é a interdisciplinaridade que une duas ou mais áreas da ciência como por exemplo a história sociológica, a demografia histórica, a antropologia histórica. Essa interdisciplinaridade chegou a originar as ciências que mesclam inclusive ciências humanas e ciências da natureza (GOFF, 2005).

Nomes como Koselleck e Pomian acreditam que o desenvolvimento dessas ciências contribui de forma positiva para a mudança epistemológica radical na teoria da história, principalmente por recusar a influência filosófica sobre ela. De acordo com eles, a ciências humanas foi precursora da concepção de que o homem não é sujeito, mas também resultado, ou seja, objeto da história (JULIÃO, 2010).

\section{CONCLUSÕES}

Conclui-se com este trabalho que a Filosofia da História passou por diversas transformações durante sua história, no geral a Filosofia da História teve uma evolução de acordo com o contexto social da época, inicialmente com a forte influência da igreja a produção sobre os estudos históricos era centrado na figura de Deus, e com o passar do tempo e a perda de força da igreja católica e o surgimento do iluminismo ocasionou uma mudança filosófica nos historiadores, que agora buscavam o desligamento da igreja e a busca pela razão em seus trabalhos, em seguida já no século XIX e século XX, a filosofia da história sofreu novas mudanças de paradigmas, e agora estava inclinada a trabalhar os aspectos da Teoria da História ou Epistemologia devido ao forte cunhos científico da pesquisa acadêmica atual. Pode se afirmar que a própria evolução da Filosofia da História é um tema de estudo histórico a qual é possível realizar análises dos trabalhos dos historiadores de cada período e sua relação com o contexto social, político e religioso a qual estavam inseridos e tentar entender o caminho que a Filosofia da História irá tomar no contexto atual.

\section{REFERÊNCIAS}

ASSIS, A. A.. Jörn Rüsen contra a compensação. Intelligere, v.3, n.2, p.13-33, 2017.

BARROS, M. A.. Filosofia da História. 2009.

BOURDÉ, G.; MARTIN, H.. As escolas históricas. Publicações Europa-América, 1983.

CLARK, G.. Uma visão cristã dos homens e do mundo. Brasília: Monergismo, 2013.

COLLINGWOOD, R. G.. A Ideia da História. Lisboa: Presença, 1972.

GOFF, J. L.. A história nova. São Paulo: Martins Fontes, 2005

ITTLE, D.. Filosofia da História. In: ZALTA, E. N.. The stanford encyclopedia of philosophy. Metaphysics Research Lab, Stanford University, 2016.
JULIÃO, J. N.. Ensaio de Introdução à Filosofia da História. Veritas, Porto Alegre, v.55, n.3, 2010.

NERI, L. B.. O sentido da história em Karl Löwith: escatologia, progresso e secularização na obra O Sentido da História. 2019.

PECORARO, R.. Filosofia da história. Schwarcz-Companhia das Letras, 2009.

PIMENTA, P. P.. Nota sobre as origens da filosofia da história. Cadernos de Filosofia Alemã: Crítica e Modernidade, v.19, n.2, p.13-25, 2014.

ROIZ, D. S.. Um fim das filosofias da história?. Projeto História: Revista do Programa de Estudos Pós-Graduados de História, v.36, n.1, 2008.

SILVA, D. G.. A filosofia da história em de Civitate Dei de Santo Agostinho. 2017.

A CBPC - Companhia Brasileira de Produção Científica (CNPJ: 11.221.422/0001-03) detém os direitos materiais desta publicação. Os direitos referem-se à publicação do trabalho em qualquer parte do mundo, incluindo os direitos às renovações, expansões e disseminaç̃ões da contribuição, bem como outros direitos subsidiários. Todos os trabalhos publicados eletronicamente poderão posteriormente ser publicados em coletâneas impressas sob coordenação da Sustenere Publishing, da Companhia Brasileira de Produção Científica e seus parceiros autorizados. Os (as) autores (as) preservam os direitos autorais, mas não têm permissão para a publicação da contribuição em outro meio, impresso ou digital, em português ou em tradução. 